\title{
THE EFFECT OF ANNEALING ON THE MECHANICAL PROPERTIES OF NI 201 ALLOY
}

\author{
Mariia ZIMINA, Jan VÍT \\ Research Center Rez (CVR), Ltd., Hlavní 130, 25600, Husinec, Czech Republic, EU, \\ mariia.zimina@cvrez.cz
}

https://doi.org/10.37904/metal.2020.3586

\begin{abstract}
Commercial Nickel 201 alloy is widely used as a sealing material in applications under extreme temperatures and pressures. This study was designed to confirm the ability of the alloy to recover after annealing in a short time. After annealing at $950{ }^{\circ} \mathrm{C}$ in a vacuum chamber, tensile testing was performed on the specimens after $12,60,108,168,288 \mathrm{~h}$ and $312 \mathrm{~h}$ of natural aging. The results were compared with non-annealed state. It was shown that the significant decrease of yield stress and ultimate tensile strength occurs after annealing. With increasing recovery time after annealing, the slight decrease of yield stress was observed up to $240 \mathrm{~h}$. After $288 \mathrm{~h}$ the yield stress slightly increased. The microstructure of annealed specimens was analyzed using electron back-scatter diffraction, and the effect was confirmed by subgrain-recrystallized grain ratio calculations. Obtained stress-strain curves also confirm that this material can be safely used for the sealing manufacturing after $312 \mathrm{~h}$ after annealing without significant degradation. So, the attainability of the required parameters is reached.
\end{abstract}

Keywords: Ni 201, nickel alloy, mechanical properties, annealing, microstructure

\section{INTRODUCTION}

Nickel-base alloys are primarily used in applications where high-strength properties and high ductility at elevated temperatures are desired, e.g. fastening. Their low gas content, corrosion resistance, particularly to caustic environments [1-3], is favorable for many industrial applications, such as a candidate material for the container for nuclear waste repository [4] and advanced turbine blades. However, the most typical application for more simple nickel alloys, e.g. Nickel 200 and 201 Alloy, when the other special properties of nickel alloys are not required, are food-processing equipment, chemical shipping drums, aerospace and missile components and piping [5]. Nickel 201 is preferred to Nickel 200 for applications involving exposure to temperatures above $316^{\circ} \mathrm{C}$, such as seal or gaskets. Due to the face-center cubic structure, alloy is subject to rapid strain hardening, which gives it an increased formability, especially in annealed condition, at room temperature (RT) making it adoptable to the cold fabrication. Excellent formability in annealed condition is a great advantage of the alloy for the sealing applications. However, there are limitations of the time-usage of the alloy after annealing [6]. This study is designed to confirm usability of this material after annealing for the seal/gasket part of pressure vessels construction and to prove attainability of required system parameters. To investigate the effect of annealing on mechanical properties and recovery properties of commercial Nickel 201 alloy, the series of tensile tests at RT were conducted following by microstructural observations described in this paper.

\section{MATERIAL AND SPECIMENS}

Commercial Nickel 201 (Ni201) alloy with nominal chemical composition in Table 1 was used for the study. The alloy was as-cast at $650^{\circ} \mathrm{C}$ during $3 \mathrm{~h}$. The cast $8 \mathrm{~mm}$ bar was used for the specimen preparation. Round tensile specimens with the diameter of $4 \mathrm{~mm}$ and gauge length of $28 \mathrm{~mm}$ were cut from the bar. Specimens were further annealed in the vacuum furnace CLASIC 10010VAK to avoid surface oxidation at $950{ }^{\circ} \mathrm{C}$ for $2 \mathrm{~h}$ with a heating rate of $3^{\circ} \mathrm{C} \cdot \mathrm{min}^{-1}$ (during $5 \mathrm{~h}$ ) and were quenched using controlled cooling during $12 \mathrm{~h}$. 
Table 1 Nominal chemical composition of the melt of Ni201 alloy (wt\%)

\begin{tabular}{|c|c|c|c|c|c|c|}
\hline $\mathbf{N i}$ & $\mathbf{C}$ & $\mathbf{C o}$ & $\mathbf{C u}$ & $\mathbf{F e}$ & $\mathbf{M g}$ & $\mathbf{M n}$ \\
\hline 99.43 & 0.016 & 0.001 & 0.009 & 0.01 & 0.011 & 0.25 \\
\hline $\mathbf{S}$ & $\mathbf{S i}$ & $\mathbf{T i}$ & $\mathbf{P b}$ & $\mathbf{P}$ & $\mathbf{S n}$ & \\
\hline 0.001 & 0.24 & 0.001 & $<0.001$ & $<0.005$ & $<0.005$ & \\
\hline
\end{tabular}

\section{EXPERIMENTAL TECHNIQUES}

Tensile testing was performed using universal servo-hydraulic tensile testing machine Instron 8874 according to ASTM E8 standard. Constant extension rate of $1 \mathrm{~mm} \cdot \mathrm{min}^{-1}$ were chosen and tests were performed up to rupture at RT. Round tensile specimens of as-received Nickel 201 alloy, alloy after annealing and $12 \mathrm{~h}$ of quenching, and further after $60,108,168,240,288$ and $312 \mathrm{~h}$ of RT natural aging were examined in order to obtain the recovery properties of the alloy. Annealed specimens were prepared for electron-back scattered diffraction (EBSD) analysis using standard metallographic techniques and were kept in the SEM chamber during the aging to eliminate unfavorable thermal effects. The microstructure was studied using Tescan Lyra3 scanning-electron microscope by acquisition of EBSD maps of $2 \times 2 \mathrm{~mm}^{2}$ with a step size of $5 \mu \mathrm{m}$ at accelerating beam voltage of $20 \mathrm{kV}$.

\section{RESULTS}

The microstructure of as-received material and the material after annealing is shown in maps in Figure 1. The initial grain size of $10 \mu \mathrm{m}$ has increased after annealing and controlled quenching up to $14 \mu \mathrm{m}$ (Figures 1a, b). The recrystallized fraction maps were obtained using misorientation angles for subgrains $-3^{\circ}$ and for recrystallized grains $-15^{\circ}$. The structure with misorientation angle less than $3^{\circ}$ is considered as deformed. In Figure 2, the evolution of fraction of deformed, subgrains and fully recrystallized grains with respect to the annealing time is shown. After annealing (12 h), the large amount of subgrains, $74 \%$, is present compared to the mostly deformed as-received structure $(-24 \mathrm{~h})$. Small amount of fully recrystallized grains is also observed (3.6\%) after annealing. Long-term natural aging starting from $168 \mathrm{~h}$ after annealing results in the material's recovery and grain growth up to $58 \mu \mathrm{m}$ (Figures 1c and 2). The recrystallized fraction is drastically increased up to about $80 \%$, and almost no deformed structure is observed. Increasing aging time $(240 \mathrm{~h}$ ) leads to the increase of the subgrains-recrystallized grains ratio from 0.2 to 2 , however, no further grain growth was detected. After $288 \mathrm{~h}$ this ratio decreases to the values obtained after $168 \mathrm{~h}$ and remains similar after $312 \mathrm{~h}$ of aging. This spontaneous change of the subgrains-recrystallized grains ratio with no effect on the grain size was confirmed by the results of tensile tests.

Table 2 Mechanical properties of Ni201 alloy in several aging conditions

\begin{tabular}{|l|c|c|c|}
\hline Material & $\begin{array}{c}\text { Yield stress } \\
(\mathrm{MPa})\end{array}$ & $\begin{array}{c}\text { Ultimate tensile } \\
\text { strength }(\mathrm{MPa})\end{array}$ & $\begin{array}{c}\text { Max. strain } \\
(-)\end{array}$ \\
\hline As-received, non-annealed & 108 & 560 & 0.2 \\
\hline 12 h of controlled quenching after annealing & 45 & 394 & 0.45 \\
\hline $60 \mathrm{~h}$ after annealing & 44 & 391 & 0.45 \\
\hline $108 \mathrm{~h}$ after annealing & 27 & 396 & 0.46 \\
\hline $168 \mathrm{~h}$ after annealing 26.6 & 17 & 369 & 0.41 \\
\hline 240 h after annealing 29.6 & 14 & 358 & 0.435 \\
\hline 288 h after annealing 1/7 & 19.5 & 381 & 0.42 \\
\hline 312 h after annealing & 15.5 & 357 & 0.52 \\
\hline
\end{tabular}


Mechanical properties of al studied material conditions obtained during the testing are summarized in Table 2. Engineering stress-strain curves and the dependences of UTS, YS and elongation on time with respect to the annealing are presented in Figures $3 \mathbf{~ a , ~ b . ~ A d d i t i o n a l ~ t e s t s ~ a f t e r ~} 60$ and $108 \mathrm{~h}$ were performed to study the trend of the aging effect on the material's recovery. Ist was shown that the significant decrease of yield stress and ultimate tensile strength occurs after annealing and $12 \mathrm{~h}$ of controlled quenching. With increasing RT aging time after annealing, the slight decrease of yield stress was observed up to $240 \mathrm{~h}$. After $288 \mathrm{~h}$ the slight increase of the yield stress was observed, and at $312 \mathrm{~h}$ the value are similar within the measurement error, which corresponds also to the acquired recrystallization fraction ratios.

\section{(a) As-received (-24 h)}

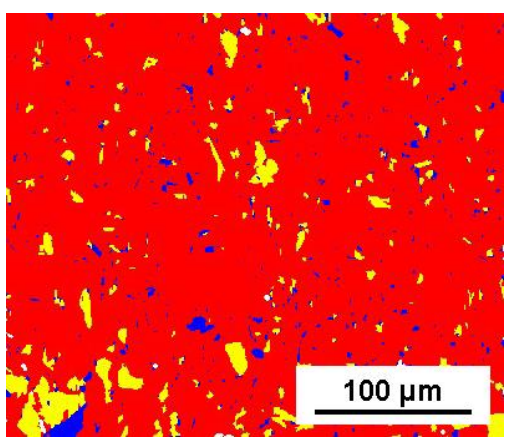

(d) Annealed and aged for $240 \mathrm{~h}$

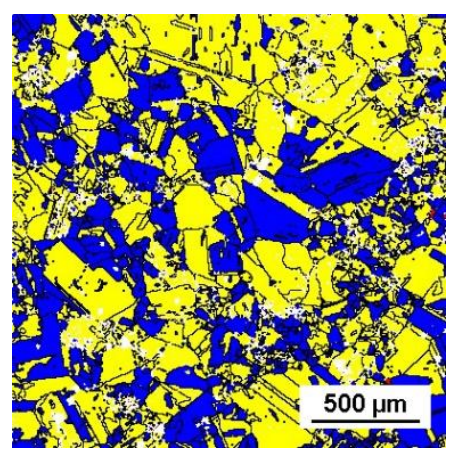

(b) Annealed and $12 \mathrm{~h}$ of controlled cooling (12 h)

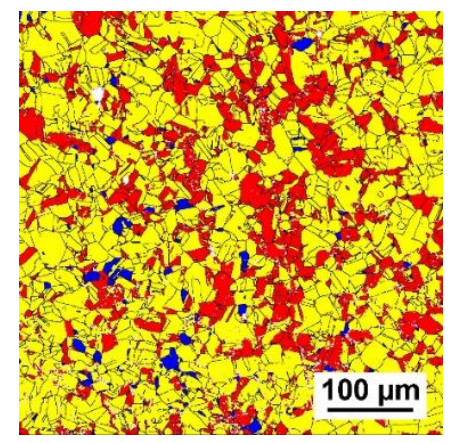

(e) Annealed and aged for $288 \mathrm{~h}$

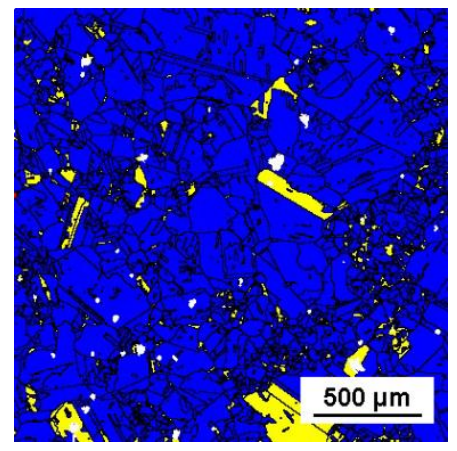

(c) Annealed and aged for $168 \mathrm{~h}$

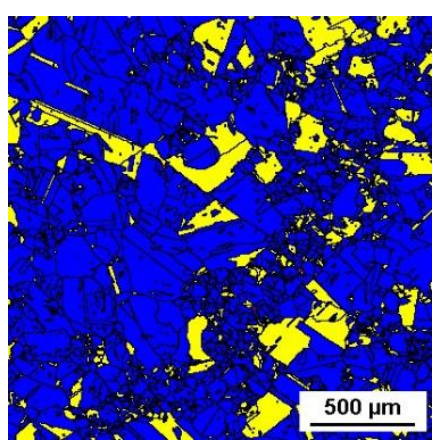

(f) Annealed and aged for $312 \mathrm{~h}$

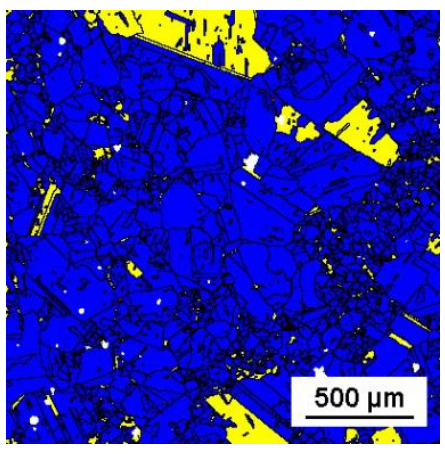

Figure 1 Recrystallization fraction EBSD maps of a) as-received, b) annealed and quenched, c-f) aged Ni 201 commercial alloy

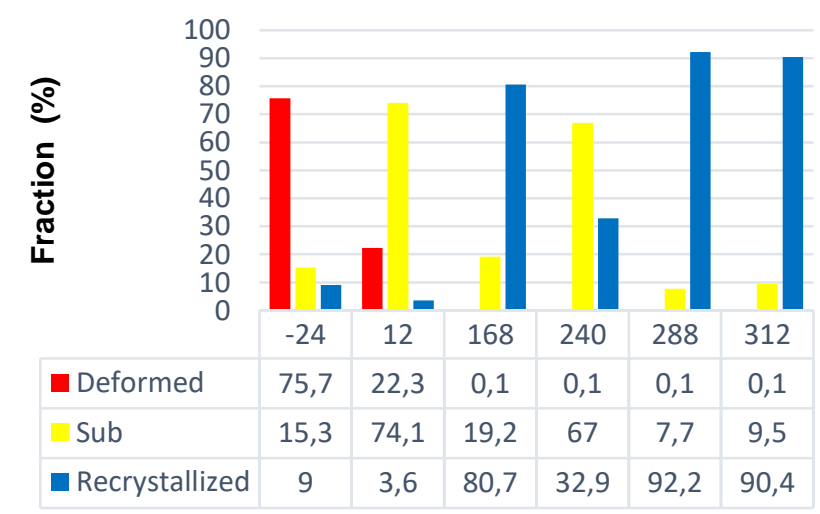

Time after annealing (h)

Figure 2 Fraction of deformed, subgrains and fully recrystallized grains in natural aged Ni201 alloy with respect to the annealing time 

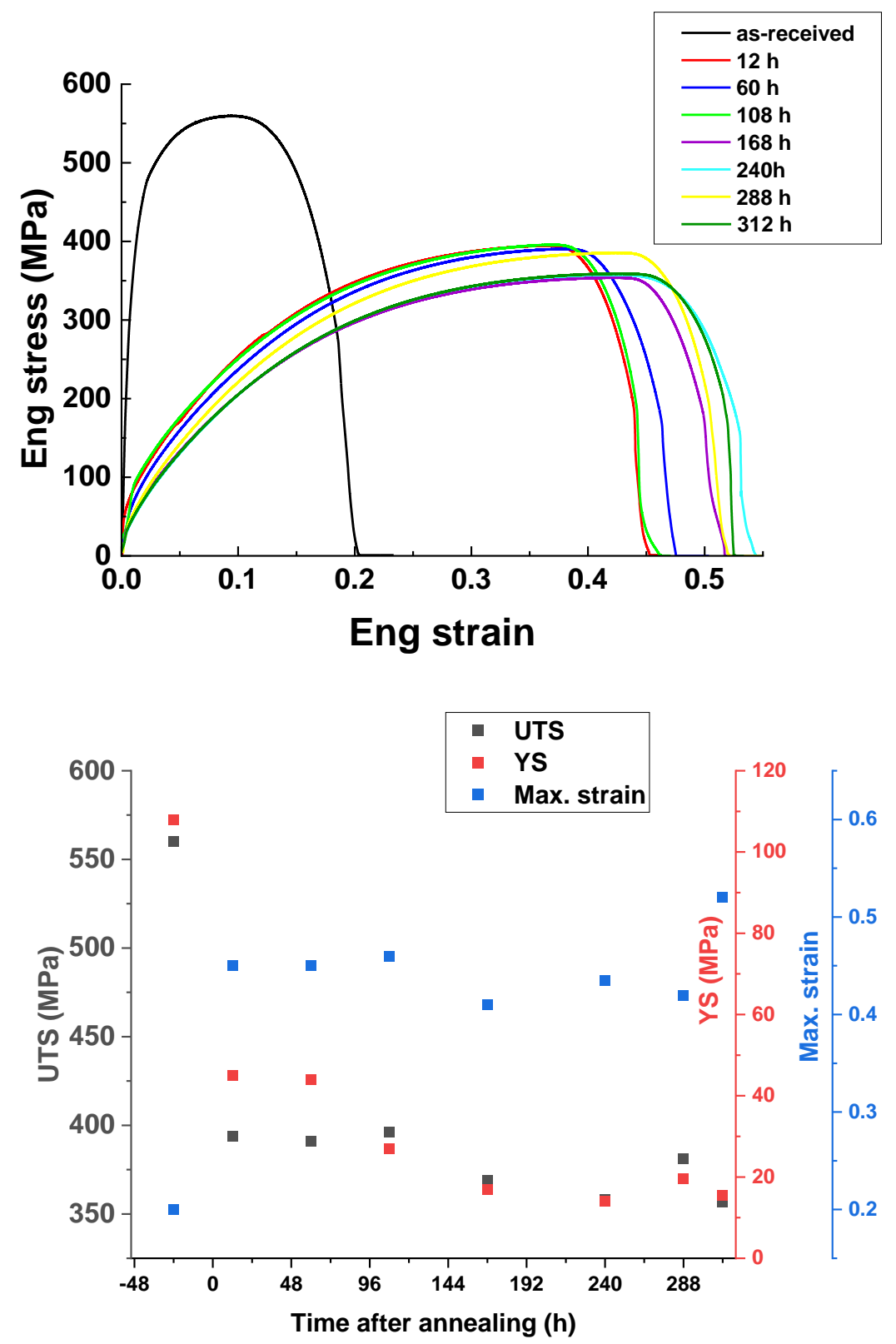

Figure 3 a) Stress-strain deformation curves for Ni201 alloy in as-received and after annealing conditions and b) mechanical properties dependences on the aging time

\section{DISCUSSION AND SUMMARY}

The results of tensile testing of commercial Ni201 alloy were summarized and compared to the microstructure observations. It was shown that after 2 hours of annealing at $950{ }^{\circ} \mathrm{C}$ and $12 \mathrm{~h}$ of controlled cooling a decrease in yield strength, tensile strength and, conversely, a two-times increase in elongation occur.

The recovery properties of Ni201 alloy after annealing, cooling and natural aging at RT were obtained. The results of tensile testing confirm the decrease of yield stress and ultimate tensile strength after $240 \mathrm{~h}$ of aging related to the increase of the subgrains-recrystallized grains ratio from 0.2 to 2 , when compared to $168 \mathrm{~h}$. This can be explained by continuous stress relief achieved in the material first after annealing and reinforced during aging. Further decrease of this ratio from 2 to 0.08 with aging time is correlated with the slight increase of mentioned mechanical properties. However, this effect is not accompanied by the grain growth. Further 
investigation of the precipitation and microstructure is needed to understand and explain the effect. Nevertheless, according to the acquired results the Ni201 alloy can be safely used as a sealing material after up to $312 \mathrm{~h}$ after conventional annealing with no significant influence on the mechanical properties. These results will be used for the design and calculation of seal/gasket parts for the construction of pressure vessels.

\section{ACKNOWLEDGEMENTS}

The authors are grateful for the support of the CVR project 18D0013: "IPNOP 3D scanning of irradiated quartz samples". The presented work was financially supported by the Ministry of Education, Youth and Sport Czech Republic - project LQ1603 Research for SUSEN. This work has been realized within the SUSEN Project (established in the framework of the European Regional Development Fund (ERDF) in project CZ.1.05/2.1.00/03.0108 and of the European Strategy Forum on Research Infrastructures (ESFRI) in the project CZ.02.1.01/0.0/0.0/15_008/0000293, which is financially supported by the Ministry of Education, Youth and Sports - project LM2015093 Infrastructure SUSEN.

\section{REFERENCES}

[1] CHEEVER, D.L., MARTIN, D.C., MONROE, R.E. NASA Technical memorandum X-53441: Mechanical fastening of nickel-base alloys. NASA-G. C. Marshall Space Flight Center, 1966.

[2] GLACKIN, J.J., GOWEN, E.F. Jr. Evaluation of fasteners and fastener materials for space vehicles. Standard Pressed Steel Company, Jenkintown, Pennsylvania, Annual Report, Contract No. NAS8-11225.1966. NASA CR357.

[3] GLACKIN, J.J., GOWEN, E.F. Jr. Evaluation of fasteners and fastener materials for space vehicles. Standard Pressed Steel Company, Jenkintown, Pennsylvania, Annual Report, Contract No. NAS8-11225. 1964. RSIC 0359.

[4] BASSFORD, T.H., HOSIER, J. Nickel and its alloys. Handbook of Materials Selection. JohnWiley\&Sons, Inc., New York, 2002.

[5] REBAK, R.B., KOON, N.B. Localized corrosion resistance of high nickel alloys as candidate materials for nuclear waste repository. Effect of alloy and weldment aging at $427^{\circ} \mathrm{C}$ for up to $40,000 \mathrm{H}$. Corrosion'98: 53. Annual conference and exposition. Proceedings. San Diego, CA (United States), 1998, p. 13, paper 153.

[6] DE GEE, A.J., PALLAV, P., WERNER, A., DAVIDSON, C.L. Annealing as a mechanism of increasing wear resistance of composites. Dental Materials. 1990, vol. 6, no. 4, pp. 266-270. 